\title{
Hypoglycemia Caused by Endogenous Hyperinsulinism: A Case Study
}

\author{
Kiran Shah, Akshay Kothari, Ajay Bansode, and Tahir Aktar
}

\section{ABSTRACT}

Hypoglycemia in the absence of diabetes mellitus in a healthy individual needs' evaluation. We report a case of 45 years old female who presented with restlessness, anxiety, palpitations, excessive sweating followed by dizziness, and tremors in her hand. Eating sugar or consuming glucose water alleviated symptoms. During one such episode, the patient was taken to a nearby clinic and her capillary blood glucose was $43 \mathrm{mg} / \mathrm{dl}$. The patient was admitted for the $\mathbf{7 2}$ hours supervised fast after ruling out other systemic causes of hypoglycemia. Evaluation of critical sample showed elevated levels of insulin, c-peptide, proinsulin, as well as a decreased value of betahydroxybutyrate and a negative urine screen for oral anti-diabetic agents, a diagnosis of endogenous hyperinsulinism, was made.

Keywords: Endogenous hyperinsulinism, Hypoglycemia, Non-diabetic, 72hour supervised fast.
Submitted : May 13, 2021

Published : June 04, 2021

ISSN: 2593-8339

DOI: $10.24018 /$ ejmed.2021.3.3.877

\section{K. Shah*}

Visiting Diabetologist Dept of Medicine, Grant Govt Medical College \& Sir J J Group of Hospitals, Mumbai, India.

(e-mail: drkiranshh@gmail.com)

A. Kothari

Visiting Diabetologist Dept of Medicine, Grant Govt Medical College \& Sir J J Group of Hospitals, Mumbai, India.

(e-mail: arkothari13@gmail.com)

A. Bansode

Junior Resident Dept of Medicine,

Grant Govt Medical College \& Sir J J

Group of Hospitals, Mumbai, India.

(e-mail: bansodeajay00@gmail.com) T. Akhtar

Junior Resident Dept of Medicine, Grant Govt Medical College \& Sir J J Group of Hospitals, Mumbai, India.

(e-mail: tahir1796@gmail.com)

*Corresponding Author

\section{CASE REPORT}

Hypoglycemia (glucose $<55 \mathrm{mg} / \mathrm{dl}$ ) is rare in otherwise healthy adults, as well as in people who are not being treated for diabetes. Before beginning a hypoglycemia assessment, the Whipple's triad, which includes low plasma glucose concentration, clinical signs or symptoms associated with hypoglycemia, and resolution of signs and symptoms as plasma glucose concentration rises, should be recorded [1][3]. When signs appear, testing should be performed as soon as possible, aided by blood tests at the time of hypoglycemia to determine the etiology in cases where there is no illness or medication as a cause. A prolonged supervised fast test or mixed meal test can be performed to determine etiology. Hypoglycemia treatment should be specific to the underlying cause and may include nutritional, medical, and/or surgical interventions.

We report a case of hypoglycemia due to endogenous hyperinsulinism in a patient with no other systemic illness or medications as a known cause of hypoglycemia.
A 45 year old female non-alcoholic, non-diabetic presented with restlessness, anxiety, palpitations, excessive sweating followed by dizziness, and tremors in hand. Eating sugar or consuming glucose water alleviated symptoms. On further questioning patient experiences similar episodes one or two times per day for 1 month. During one such episode, the patient had a history of slurred speech followed by altered sensorium. She was taken to a nearby clinic and her capillary blood glucose was $43 \mathrm{mg} / \mathrm{dl}$ recorded on a glucometer. She was administered $25 \%$ intravenous glucose. She regained consciousness and her slurring of speech disappeared. Most of the episodes have occurred early morning 8-9 hours after the last meal and 3 episodes in the evening 8 hours after the last meal. No history was suggestive of chronic liver disease, renal disease, or any other systemic illness. She was not on any medications and had no history of any surgery. There is no history of pain in the abdomen, vomiting, or increased pigmentation of skin or mucosa. No history of acral enlargement, coarsening of facial features, galactorrhea, 
menstrual irregularities. No history of recurrent renal stones or fragility fractures. No family history of similar complaints. No social or psychiatric issues. She has a body mass index of $25.2 \mathrm{~kg} / \mathrm{m}^{2}$. She was normotensive and did not have acanthosis nigricans. Her routine blood parameters were within the normal range for liver and renal function tests. Her 8.00 am serum cortisol was $14 \mathrm{mg} / \mathrm{dL}$. The patient underwent a 72-hour fasting test. She had an episode of hypoglycemia at the 9th hour of fasting, blood glucose measured by glucometer was $42 \mathrm{mg} / \mathrm{dL}$ Critical sample was taken and sent for analysis (Table I).

TABLE I: CRITICAL SAMPLE RESULTS

\begin{tabular}{ccc}
\hline Parameter & $\begin{array}{c}\text { Patient 72-hour } \\
\text { fasting test result }\end{array}$ & $\begin{array}{c}\text { Endogenous } \\
\text { Hyperinsulinism }\end{array}$ \\
\hline Blood glucose mg/dL & 38 & $<55$ \\
Insulin $(\mu \mathrm{U} / \mathrm{mL})$ & 6.5 & $\geq 3$ \\
Proinsulin $(\mathrm{pmol} / \mathrm{L})$ & 5.7 & $\geq 5$ \\
C -peptide $(\mathrm{ng} / \mathrm{mL})$ & 3 & $\geq 0.2$ \\
$\begin{array}{c}\text { Beta hydroxybutyrate } \\
\text { (mmol/L) }\end{array}$ & 0.5 & $\leq 2.7$ \\
Urine screen for oral & Negative & Negative \\
antidiabetic drugs & & \\
\hline
\end{tabular}

Plasma glucose increased to $87 \mathrm{mg} / \mathrm{dL} 30$ minutes after glucagon administration, an increase of more than $25 \mathrm{mg} / \mathrm{dL}$ Anti-insulin antibodies were negative. Insulinoma was suspected, so imaging tests for localization were ordered. Imaging tests, such as abdominal computed tomography, and magnetic resonance imaging, however, failed to detect pancreatic lesions. Our being a charitable tertiary hospital octreotide scintigraphy could not be afforded. Our patient was apprehensive about undergoing invasive procedures like endoscopic ultrasonography, selective arterial calcium stimulation tests. She chose conservative medical treatment in conjunction with dietary changes. She was started on tablet diazoxide $150 \mathrm{mg}$ per day. The patient maintained fasting blood glucose values of $79-92 \mathrm{mg} / \mathrm{dL}$ and a postprandial glycemia of $108-135 \mathrm{mg} / \mathrm{dL}$. The patient's blood pressure remains normal, and no diazoxide-related side effects were reported.

\section{DISCUSSION}

Endogenous hyperinsulinism induced hypoglycemia is a category of clinically, genetically, and histologically diverse disorders marked by improper insulin secretion from pancreatic cells in the presence of low blood glucose levels [4]. Hypoglycemia in a non-diabetic healthy patient is normally caused by various etiologies. Endogenous hyperinsulinism caused by insulinoma, functional beta-cell disorders, or insulin autoimmune conditions are all possibilities in these individuals. Drugs, such as glucoselowering agents like sulphonylureas, insulin, and meglitinides, are the most common cause of hypoglycemia. Hypoglycemia has been linked to nonselective beta-blockers, pentamidine, quinolones, gatifloxacin, and even ACE inhibitors [5], [6]. Our patient was not on any medications. Hypoglycemia can result from a lack of counter-regulatory hormones. Hypoglycemia can be caused by any condition that causes ACTH deficiency or directly interferes with cortisol secretion. Cortisol levels greater than $18 \mathrm{mcg} / \mathrm{dL}$ in the morning predict a normal response, and no further testing is required. Cortisol levels below $5 \mathrm{mcg} / \mathrm{dL}$, on the other hand, are indicative of adrenal insufficiency [7]. Our patient had a basal cortisol value of $14 \mathrm{mcg} / \mathrm{dL}$. Hypoglycemia is common in the setting of critical illness, sepsis, and organ failure, and it is associated with excess glucose utilization that exceeds production in the absence of exogenous insulin treatment [8], [9]. Hepatic, renal, and cardiac failure can result in hypoglycemia because of rapid and massive hepatic destruction, decreased renal gluconeogenesis, decreased clearance of insulin, and decreased calorie intake respectively [10]-[12]. Our patient did not have any of the above clinical conditions. Malnutrition can result in hypoglycemia due to a lack of substrates for gluconeogenesis and glycogenolysis [13]. Our patient was not malnourished and had not undergone any bariatric surgery for obesity [14]. Reactive hypoglycemia is primarily due to abnormal transport of food to the small intestine [15]. Insulin autoimmune syndrome, also known as Hirata's disease, is distinguished by the presence of antibodies to insulin and/or proinsulin or insulin receptor [16]. Endogenous hyperinsulinemia is a rare cause of hypoglycemia that can be caused by insulinoma or pancreatic islet nesidioblastosis. Insulinoma primarily causes hypoglycemia while fasting, but it can also cause symptoms in the fed state. Insulin, c-peptide, and proinsulin levels are elevated during hypoglycemia, while beta-hydroxybutyrate levels are low. Our patient had similar outcomes when evaluated using gold standard the 72-hour fast test. Nesidioblastosis, which is characterized by islet hypertrophy, hyperplasia, and enlarged and hyperchromatic beta-cell nuclei, causes postprandial hypoglycemia [17]. Hypoglycemia is linked to decreased endogenous insulin secretion and increased glucose consumption by tumors in patients with non-islet cell tumors [18]. The emphasis of immediate care should be on reversing hypoglycemia. Dietary changes, medical management with alphaglucosidase inhibitors, calcium-channel blockers, diazoxide, or somatostatin analogs, and eventually surgical resection of the cause should all be adapted to the particular hypoglycemia condition. The patient's normoglycemia was re-established and sustained with diazoxide and dietary advice.

\section{CONCLUSION}

Hypoglycemia in healthy people is uncommon, and it should be investigated thoroughly. There are only a few cases of adults receiving medical attention for endogenous hyperinsulinism. This clinical case demonstrates that diazoxide can successfully treat adult endogenous hyperinsulinism with few side effects, making it a viable alternative to pancreatic surgery.

\section{CONFLICT OF INTEREST}

All authors declare there is no conflict of interest.

\section{CONSENT}

Written informed consent was obtained from the patient for publication of this case report and any accompanying images. 


\section{AUTHORS CONTRIBUTION STATEMENT}

Author and co-authors have equally contributed to the manuscript.

\section{REFERENCES}

[1] Cryer, P. E., Axelrod, L., Grossman, A. B., Heller, S. R., Montori, V. M., Seaquist, E. R., Service, F. J., \& Endocrine Society (2009). Evaluation and management of adult hypoglycemic disorders: an Endocrine Society Clinical Practice Guideline. The Journal of clinical endocrinology and metabolism, 94(3), 709-728. https://doi.org/10.1210/jc.2008-1410.

[2] Nirantharakumar, K., Marshall, T., Hodson, J., Narendran, P., Deeks, J., Coleman, J. J., \& Ferner, R. E. (2012). Hypoglycemia in nondiabetic in-patients: clinical or criminal?. PloS one, 7(7), e40384. https://doi.org/10.1371/journal.pone.0040384.

[3] Whipple, A. O., \& Frantz, V. K. (1935). Adenoma of islet cells with hyperinsulinism: A REVIEW. Annals of surgery, 101(6), 1299-1335. https://doi.org/10.1097/00000658-193506000-00001.

[4] Demirbilek, H., Rahman, S. A., Buyukyilmaz, G. G., \& Hussain, K. (2017). Diagnosis and treatment of hyperinsulinaemic hypoglycaemia and its implications for paediatric endocrinology. International journal of pediatric endocrinology, 2017, 9. https://doi.org/10.1186/s13633017-0048-8.

[5] El Ghandour, S., \& Azar, S. T. (2015). Dysglycemia associated with quinolones. Primary care diabetes, 9(3), 168-171. https://doi.org/10.1016/j.pcd.2014.10.006.

[6] Elshimy, G., Techathaveewat, P., Alsayed, M., Jyothinagaram, S., \& Correa, R. (2019). Simple Reason for Hypoglycemia: ACE Inhibitorinduced Severe Recurrent Hypoglycemia in a Nondiabetic Patient. Cureus, 11(8), e5449. https://doi.org/10.7759/cureus.5449.

[7] Bornstein, S. R., Allolio, B., Arlt, W., Barthel, A., Don-Wauchope, A. Hammer, G. D., Husebye, E. S., Merke, D. P., Murad, M. H., Stratakis, C. A., \& Torpy, D. J. (2016). Diagnosis and Treatment of Primary Adrenal Insufficiency: An Endocrine Society Clinical Practice Guideline. The Journal of clinical endocrinology and metabolism, 101(2), 364-389. https://doi.org/10.1210/jc.2015-1710.

[8] Maitra, S. R., Wojnar, M. M., \& Lang, C. H. (2000). Alterations in tissue glucose uptake during the hyperglycemic and hypoglycemic phases of sepsis. Shock (Augusta, Ga.), 13(5), 379-385. https://doi.org/10.1097/00024382-200005000-00006.
[9] Plummer, M. P., \& Deane, A. M. (2016). Dysglycemia and Glucose Control During Sepsis. Clinics in chest medicine, 37(2), 309-319. https://doi.org/10.1016/j.ccm.2016.01.010.

[10] Felig, P., Brown, W. V., Levine, R. A., \& Klatskin, G. (1970). Glucose homeostasis in viral hepatitis. The New England journal of medicine, 283(26), 1436-1440. https://doi.org/10.1056/NEJM197012242832604.

[11] Moen, M. F., Zhan, M., Hsu, V. D., Walker, L. D., Einhorn, L. M., Seliger, S. L., \& Fink, J. C. (2009). Frequency of hypoglycemia and its significance in chronic kidney disease. Clinical journal of the American Society of Nephrology: CJASN, 4(6), 1121-1127. https://doi.org/10.2215/CJN.00800209.

[12] Benzing, G., 3rd, Schubert, W., Sug, G., \& Kaplan, S. (1969). Simultaneous hypoglycemia and acute congestive heart failure. Circulation, 40(2), 209-216. https://doi.org/10.1161/01.cir.40.2.209.

[13] Saudek, C. D., \& Felig, P. (1976). The metabolic events of starvation. The American journal of medicine, 60(1), 117-126. https://doi.org/10.1016/0002-9343(76)90540-4.

[14] Raverdy, V., Baud, G., Pigeyre, M., Verkindt, H., Torres, F., Preda, C., Thuillier, D., Gélé, P., Vantyghem, M. C., Caiazzo, R., \& Pattou, F. (2016). Incidence and Predictive Factors of Postprandial Hyperinsulinemic Hypoglycemia After Roux-en-Y Gastric Bypass: A Five year Longitudinal Study. Annals of surgery, 264(5), 878-885. https://doi.org/10.1097/SLA.0000000000001915.

[15] Salehi, M., Vella, A., McLaughlin, T., \& Patti, M. E. (2018) Hypoglycemia After Gastric Bypass Surgery: Current Concepts and Controversies. The Journal of clinical endocrinology and metabolism, 103(8), 2815-2826. https://doi.org/10.1210/jc.2018-00528.

[16] Ismail A. A. (2016). The insulin autoimmune syndrome (IAS) as a cause of hypoglycaemia: an update on the pathophysiology, biochemical investigations and diagnosis. Clinical chemistry and laboratory medicine, 54(11), 1715-1724. https://doi.org/10.1515/cclm-2015-1255.

[17] Klöppel, G., Anlauf, M., Raffel, A., Perren, A., \& Knoefel, W. T. (2008). Adult diffuse nesidioblastosis: genetically or environmentally induced? Human pathology, 39(1), 3-8. https://doi.org/10.1016/j.humpath.2007.09.010.

[18] Nauck, M. A., Reinecke, M., Perren, A., Frystyk, J., Berishvili, G., Zwimpfer, C., Figge, A. M., Flyvbjerg, A., Lankisch, P. G., Blum, W. F., Klöppel, G., Schmiegel, W., \& Zapf, J. (2007). Hypoglycemia due to paraneoplastic secretion of insulin-like growth factor-I in a patient with metastasizing large-cell carcinoma of the lung. The Journal of clinical endocrinology and metabolism, 92(5), 1600-1605. https://doi.org/10.1210/jc.2006-2573. 